\title{
Photodegradation of methyl red by advanced and homogeneous photo- Fenton's processes: A comparative study and kinetic approach
}

\author{
L. Gomathi Devi, * K. S. Anantha Raju and S. Girish Kumar \\ Received 16th January 2009, Accepted 6th May 2009 \\ First published as an Advance Article on the web 1st June 2009 \\ DOI: 10.1039/b900936a
}

\begin{abstract}
The degradation of methyl red (MR), an azo dye, was carried out by the homogeneous photo-Fenton's process (HPFP) and the advanced photo-Fenton's process (APFP) using symmetrical peroxides such as hydrogen peroxide and ammonium persulfate (APS) as oxidants. The APFP showed higher efficiency than their homogeneous counterparts even at high dye concentrations due to the faster reduction of $\mathrm{Fe}^{3+}$ to $\mathrm{Fe}^{2+}$ ions on the iron surface. $\mathrm{H}_{2} \mathrm{O}_{2}$ proved to be a better oxidant for both the processes. However, APS efficiently inhibited the precipitation of iron oxy hydroxides at higher dosage of iron powder compared to $\mathrm{H}_{2} \mathrm{O}_{2}$ by providing excess acidity to the reaction medium. The rate constant for the kinetics of decolorisation by various oxidation processes is of the order: $\mathrm{Fe}^{0} / \mathrm{H}_{2} \mathrm{O}_{2} / \mathrm{UV}>\mathrm{Fe}^{0} / \mathrm{H}_{2} \mathrm{O}_{2} /$ dark $>\mathrm{Fe}^{0} / \mathrm{APS} / \mathrm{UV}>\mathrm{Fe}^{2+} / \mathrm{H}_{2} \mathrm{O}_{2} / \mathrm{UV}>\mathrm{Fe}^{0} / \mathrm{UV}>\mathrm{Fe}^{0} / \mathrm{APS} /$ dark $>\mathrm{Fe}^{0} /$ dark $\approx \mathrm{H}_{2} \mathrm{O}_{2} / \mathrm{UV}>\mathrm{Fe}^{2+} / \mathrm{APS} /$ $\mathrm{UV}>\mathrm{APS} / \mathrm{UV}>\mathrm{Fe}^{2+} / \mathrm{H}_{2} \mathrm{O}_{2} /$ dark $>\mathrm{Fe}^{2+} / \mathrm{APS} /$ dark $\approx \mathrm{Fe}^{2+} / \mathrm{UV}$. The degradation reaction was followed by UV-visible and GC-MS spectroscopic techniques. Based on the intermediates obtained, probable degradation mechanisms have been proposed. It was found that the initial mechanism in the APFP involves the reduction of azo groups to amines while in the case of HPFP it leads to the formation of hydroxylated products due to the oxidation of azo groups.
\end{abstract}

\section{Introduction}

Azo dyes contain one or more nitrogen to nitrogen double bond $(-\mathrm{N}=\mathrm{N}-)$ and they constitute almost $80 \%$ of the reactive dyes. Most of the azo dyes are not biodegradable by aerobic treatment processes. ${ }^{1}$ However, azo dyes can be decolorised by anaerobic treatment, ${ }^{2,3}$ but this leads to the production of toxic by-products such as aromatic amines. ${ }^{4}$ Advanced oxidation processes involving Fenton's and photo-Fenton's process for the degradation of organic dyes are extensively reported in the literature. $^{5-10}$ The main advantage of photo-Fenton's process are; reagents are easily available, cheap and cost effective. Further no scattering of light takes place, contact between the pollutants and the catalyst is high since the reaction is homogeneous. The disadvantage of a homogeneous process is the non-reusability of the catalyst which hinders its commercial application. Therefore, many researchers have investigated the applications of iron incorporated zeolites ${ }^{11}$ and iron minerals ${ }^{12}$ as catalytic material for the oxidation of organic pollutants. Lucking et al. ${ }^{13}$ tested the catalytic properties of iron powder, graphite and activated carbon for the oxidation of 4-chlorophenol in aqueous solution with hydrogen peroxide. They concluded that iron powder could be used to replace iron salts as a catalyst to the Fenton's process. Zero Valent Metallic Iron (ZVMI) powder is an environmental friendly reducing agent which has been widely used for environmental remediation in recent years. In the present study, we compare the efficiency of the homogeneous photo-Fenton process (HPFP) with the Advanced photo-Fenton process

Department of Post Graduate Studies in Chemistry, Central College Campus, Dr B. R. Ambedkar Veedi, Bangalore University, Bangalore, 560 001, India. E-mail: gomatidevi_naik@yahoo.co.in; Fax: +91 08022961331; Tel: +91 080-22961336
(APFP) for the degradation of the azo dye - methyl red (MR). Though $\mathrm{H}_{2} \mathrm{O}_{2}$ is extensively used in Fenton's process, few attempts have been made towards the use of peroxy disulfate as an oxidant. In view of this, the main focus is on the utilization of symmetrical peroxides like hydrogen peroxide and ammonium persulfate (APS) as the oxidants in the Fenton's and photoFenton's process.

\section{Experimental section}

\subsection{Materials and methods}

$\mathrm{MR}$, methyl alcohol, APS, ferrous oxalate $\left(\mathrm{FeC}_{2} \mathrm{O}_{4}\right)$, iron powder (electrolytic, 300 mesh size, 95\% purity) and hydrogen peroxide $(50 \%)$ were obtained from S. D. Fine Chemicals, Bombay, India and were used as received. The structure of the dye is shown in Scheme 1. The molecular formula of MR is $\mathrm{C}_{15} \mathrm{H}_{15} \mathrm{~N}_{3} \mathrm{O}_{2}$ and the molecular weight is 269 .

\subsection{Experimental procedure}

All the experiments were performed in a glass reactor of one litre capacity whose surface area is $176 \mathrm{~cm}^{2}$. The light source used was a medium pressure mercury vapor lamp of $125 \mathrm{~W}$. The photon flux of the light source was found to be $7.75 \mathrm{~mW} \mathrm{~cm} \mathrm{~cm}^{-2}$ as determined by ferrioxalate actinometry and the wave length emission is in the range of $350-400 \mathrm{~nm}$. The experiments were performed in the presence of atmospheric oxygen using distilled water. In a typical experiment of HPFP, $200 \mathrm{ml}$ of $10 \mathrm{ppm}$ dye solution was taken along with iron ion solution and was exposed directly to the light. The $\mathrm{pH}$ of the solution reduces from 6.6 to 2.3 and it was adjusted to 3 using dilute $\mathrm{NaOH}$. In APFP, pH of the dye solution after the addition of iron powder was found to 
<smiles>CN(C)c1ccc(N=Nc2ccccc2C(=O)O)cc1</smiles>

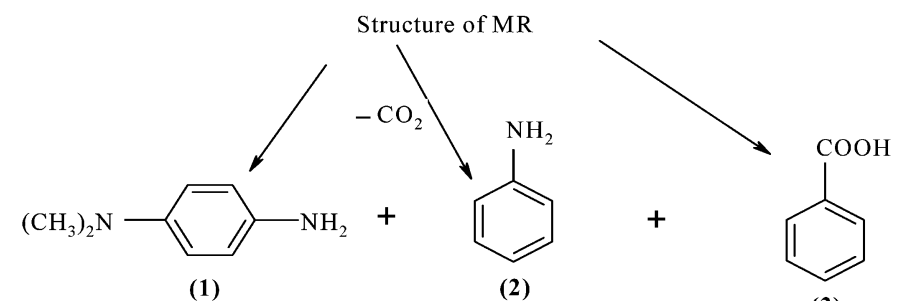

(1)

(2)<smiles>Oc1ccc(O)cc1</smiles><smiles>[Tl]C1CCCCC1</smiles>

(3)<smiles>[3H]CC(=O)[O-]</smiles><smiles>O=[N+]([O-])c1ccccc1</smiles><smiles>c1ccccc1</smiles>

(6)
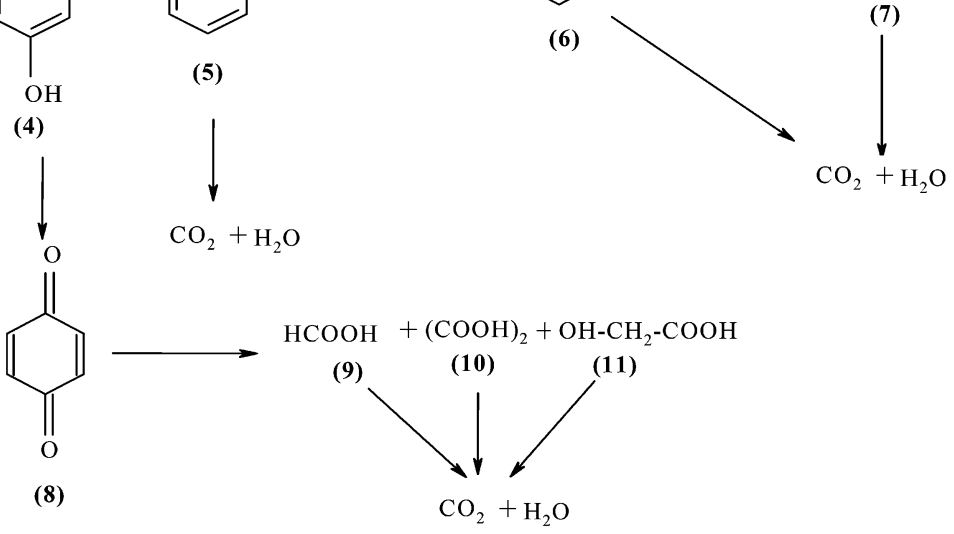

Scheme 1 Probable degradation pathway for MR by APFP.

be 6.6 and it was adjusted to 3 by adding dilute $\mathrm{H}_{2} \mathrm{SO}_{4}$. The oxidant of desired concentration was added in both the process at the beginning of the experiment.

\subsection{Analytical methods}

The solution was taken out from the reactor at definite time intervals and was centrifuged. The centrifugates were analyzed by UV-visible spectroscopy using Shimadzu UV-1700 Pharmaspec UV-visible spectrophotometer. The concentration of the dye was calculated from the standard calibration curve at its characteristic $\lambda_{\max }$ of MR dye. The centrifugates were extracted into non-aqueous medium and were subjected to GC-MS analysis using GC-MS-QP 5000 Shimadzu mass spectrometer to identify the photo products during the course of the reaction.

\section{Results and discussion}

\subsection{The various possible reactions taking place at the iron} surface/iron ions with the oxidants are illustrated as follows

Iron surface gets oxidized in acidic medium generating ferrous ions $\left(\mathrm{Fe}^{2+}\right)$.

$$
\mathrm{Fe}^{0} \stackrel{\mathrm{H}^{+}}{\longrightarrow} \mathrm{Fe}^{2+}
$$

Alternatively these ions can also be generated by the reaction of iron surface with $\mathrm{H}_{2} \mathrm{O}_{2} . \mathrm{Fe}^{2+}$ ions so formed are partially adsorbed on the iron surface. These adsorbed $\mathrm{Fe}^{2+}$ ions can react with $\mathrm{H}_{2} \mathrm{O}_{2}$ leading to the generation of hydroxyl radicals.

$$
\begin{gathered}
\mathrm{Fe}^{0}+\mathrm{H}_{2} \mathrm{O}_{2} \rightarrow \mathrm{Fe}^{2+} \text {-surface } \\
\mathrm{Fe}^{2+} \text {-surface }+\mathrm{H}_{2} \mathrm{O}_{2} \rightarrow \mathrm{Fe}^{3+}+\mathrm{OH}^{\cdot}+\mathrm{OH}^{-}
\end{gathered}
$$

If these $\mathrm{Fe}^{2+}$ ions are not partially adsorbed, they can diffuse into the bulk of the solution generating hydroxyl anions. $\mathrm{Fe}^{0}$ initially oxidizes to $\mathrm{Fe}^{2+}$ by losing two electrons as shown in eqn (4). Two electrons are transferred to electron acceptors like $\mathrm{H}_{2} \mathrm{O}_{2}$ which can form two hydroxide ions as shown in eqn (5). On adding eqn (4) and (5) we get eqn (6).

$$
\mathrm{Fe}^{0} \stackrel{\mathrm{H}^{+}}{\longrightarrow} \mathrm{Fe}^{2+}+2 \mathrm{e}^{-}
$$

$$
\begin{gathered}
\mathrm{H}_{2} \mathrm{O}_{2}+2 \mathrm{e}^{-} \rightarrow 2 \mathrm{OH}^{-} \\
\mathrm{Fe}^{0}+\mathrm{H}_{2} \mathrm{O}_{2} \rightarrow \mathrm{Fe}^{2+}+2 \mathrm{OH}^{-}
\end{gathered}
$$

The oxidant APS can react with iron surface forming sulfate and ferrous ions. 


$$
\mathrm{Fe}^{0}+\mathrm{S}_{2} \mathrm{O}_{8}{ }^{2-} \rightarrow 2 \mathrm{SO}_{4}^{2-}+\mathrm{Fe}^{2+}
$$

The $\mathrm{Fe}^{2+}$ ions generated in the above reactions can further react with the respective oxidant molecules generating free radicals and simultaneously getting oxidized to form $\mathrm{Fe}^{3+}$ ions.

$$
\begin{gathered}
\mathrm{Fe}^{2+}+\mathrm{H}_{2} \mathrm{O}_{2} \rightarrow \mathrm{Fe}^{3+}+\mathrm{OH}^{\cdot}+\mathrm{OH}^{-} \\
\mathrm{Fe}^{2+}+\mathrm{S}_{2} \mathrm{O}_{8}^{2-} \rightarrow \mathrm{Fe}^{3+}+\mathrm{SO}_{4}^{2-}+\mathrm{SO}_{4}^{-}
\end{gathered}
$$

In eqn (3), $\mathrm{Fe}^{2+}$ ions formed on the solid iron surface can react with the oxidizing agent whose rate constant is $6 \times 10^{-2} \mathrm{M}^{-1} \mathrm{~s}^{-1}$, while in eqn (8) it is the free $\mathrm{Fe}^{2+}$ ions in the solution that react with the oxidants which shows a rate constant of $76 \mathrm{M}^{-1} \mathrm{~s}^{-1}$. Though the nature of the products remains same in both the cases, the rate of formation of $\mathrm{Fe}^{3+}$ ions is faster in the homogeneous condition [eqn (9)]..$^{14}$

Ferric ions $\left(\mathrm{Fe}^{3+}\right)$ so formed can either react with molecules of water or $\mathrm{H}_{2} \mathrm{O}_{2}$ as represented in the following way:

(i) Ferric ions $\left(\mathrm{Fe}^{3+}\right)$ on reaction with water form an hydroxo complex. This complex under $\mathrm{UV}$-irradiation generates $\mathrm{Fe}^{2+}$ ions and hydroxyl radicals.

$$
\begin{aligned}
& \mathrm{Fe}^{3+}+\mathrm{H}_{2} \mathrm{O} \Leftrightarrow\left[\mathrm{Fe}(\mathrm{OH})^{2+}\right]+\mathrm{H}^{+} \\
& {\left[\mathrm{Fe}(\mathrm{OH})^{2+}\right]+\mathrm{h} v \rightarrow \mathrm{Fe}^{2+}+\cdot \mathrm{OH}}
\end{aligned}
$$

(ii) $\mathrm{Fe}^{3+}$ ions can also react with $\mathrm{H}_{2} \mathrm{O}_{2}$ leading to the formation of $\mathrm{Fe}^{2+}$ ions along with hydroperoxyl radicals. Further, so formed hydroperoxyl radicals can reduce $\mathrm{Fe}^{3+}$ ions, along with the generation of hydroxyl radicals. The $\mathrm{Fe}^{2+}$ ions are thus formed in two stages which can actively participate in the cyclic Fenton's process.

$$
\begin{gathered}
\mathrm{Fe}^{3+}+\mathrm{H}_{2} \mathrm{O}_{2} \rightarrow \mathrm{Fe}^{2+}+{ }^{\cdot} \mathrm{O}_{2} \mathrm{H}+\mathrm{H}^{+} \\
\mathrm{Fe}^{3+}+{ }^{\circ} \mathrm{O}_{2} \mathrm{H}+\mathrm{H}^{+} \rightarrow \mathrm{Fe}^{2+}+\mathrm{OH}^{\cdot}+\mathrm{OH}^{-}
\end{gathered}
$$

Two molecules of sulfate radicals are produced when $\mathrm{Fe}^{3+}$ reacts with persulfate anions, which can further react with water molecule generating hydroxyl radicals.

$$
\begin{gathered}
\mathrm{Fe}^{3+}+\mathrm{S}_{2} \mathrm{O}_{8}{ }^{2-} \rightarrow 2 \mathrm{SO}_{4}^{-\cdot}+\mathrm{Fe}^{2+} \\
\mathrm{SO}_{4}^{-\cdot}+\mathrm{H}_{2} \mathrm{O} \rightarrow \mathrm{SO}_{4}^{2-}+\cdot \mathrm{OH}+\mathrm{H}^{+}
\end{gathered}
$$

The efficiency of the photo-Fenton process was compared with Fenton's process (dark). Only 12 and $32 \%$ of the dye was decolorised for the process $\mathrm{Fe}^{2+} / \mathrm{H}_{2} \mathrm{O}_{2} /$ dark and $\mathrm{Fe}^{0} / \mathrm{H}_{2} \mathrm{O}_{2} /$ dark, respectively, whereas complete decolorisation of the dye takes around 90 and $15 \mathrm{~min}$ for the above mentioned process, respectively, under UV illumination. This is due to the fact that back reduction process of $\mathrm{Fe}^{3+}$ to $\mathrm{Fe}^{2+}$ ions, is a rate determining step in dark which proceeds at a faster rate in the presence of UV light. The faster decolorisation in the APFP is attributed to the excess generation of $\mathrm{Fe}^{2+}$ ions by the iron surface which reacts with $\mathrm{H}_{2} \mathrm{O}_{2}$ generating higher numbers of hydroxyl radicals enhancing the decolorisation rate.

\subsection{Effect of $\mathrm{pH}$}

To find the optimum $\mathrm{pH}$, experiments of $\mathrm{Fe}^{0} / \mathrm{H}_{2} \mathrm{O}_{2} / \mathrm{UV}$ and $\mathrm{Fe}^{2+}$ / $\mathrm{H}_{2} \mathrm{O}_{2} / \mathrm{UV}$ were carried out at different $\mathrm{pH}$ values in the range of 1.02 to 9.5 by maintaining the other reaction parameters constant. In the $\mathrm{pH}$ range 2.5 to 3.0 , complete decolorisation takes place for both the processes $\mathrm{Fe}^{0} / \mathrm{H}_{2} \mathrm{O}_{2} / \mathrm{UV}$ and $\mathrm{Fe}^{2+} / \mathrm{H}_{2} \mathrm{O}_{2} /$ $\mathrm{UV}$ at 15 and $90 \mathrm{~min}$ respectively. This is because at $\mathrm{pH} \mathrm{3}$, it is proposed that half of the iron species exist as $\mathrm{Fe}^{3+}$ ions and half as a complex of $\mathrm{Fe}[\mathrm{OH}]^{2+}\left(\mathrm{H}_{2} \mathrm{O}\right)_{5}$ which are the dominant photo active species. ${ }^{8,15-17}$ They have the largest light absorption coefficient and show high quantum yield for hydroxyl radical generation, along with regeneration of $\mathrm{Fe}^{2+}$ ions in the wavelength range of $280-370 \mathrm{~nm} .{ }^{18}$ However, the exact ratio of these photoactive species is uncertain according to Baes and Mesmer ${ }^{19}$ and also by Barnum ${ }^{20}$ because the measurements generally suffer from uncertainty.

Beyond this optimum $\mathrm{pH}$, the degradation rate decreases slowly and in alkaline $\mathrm{pH}(>7)$ the dye resists degradation. The decrease in the decolorisation rate at lower $\mathrm{pH}(<2)$ values can be attributed to the presence of excess protons acting as hydroxyl radical scavengers according to eqn (16).

$$
\mathrm{H}^{+}+\cdot \mathrm{OH}+\mathrm{e}^{-} \rightarrow \mathrm{H}_{2} \mathrm{O}
$$

The lower efficiency at higher $\mathrm{pH}$ values $(>7)$ is due to the precipitation of iron as $\mathrm{Fe}(\mathrm{OH})_{3}$ which gets deposited on the iron surface in APFP and remains in the solution in HPFP thus blocking the transparency of the solution. This prevents the electron transfer process between $\mathrm{Fe}^{0}$ and oxidants in the APFP process thereby reducing the concentration of hydroxyl radicals in the solution. Therefore both HPFP and APFP were optimized at $\mathrm{pH} 3$.

\subsection{Effect of oxidants}

Voluminous literature can be found for the use of $\mathrm{H}_{2} \mathrm{O}_{2}$ as the oxidant in the Fenton's/photo-Fenton's process. ${ }^{5-10}$ The application of peroxy disulfate as an oxidant in the Fenton's process is least explored. Persulfate anion is the most powerful oxidant of the peroxygen family of compounds and one of the strongest oxidants used in remediation.

$$
\mathrm{S}_{2} \mathrm{O}_{8}{ }^{2-}+2 \mathrm{H}^{+}+2 \mathrm{e}^{-} \rightarrow 2 \mathrm{HSO}_{4}^{-}
$$

The standard oxidation-reduction potential for the above reaction is $2.1 \mathrm{~V}$ compared to $1.8 \mathrm{~V}$ for $\mathrm{H}_{2} \mathrm{O}_{2}$ and $1.4 \mathrm{~V}$ for peroxy monosulfate anion $\left(\mathrm{HSO}_{3}{ }^{-}\right)$. This potential is higher than the redox potential of the permanganate anion $(1.7 \mathrm{~V})$, but slightly lower than that of ozone (2.2 V). In addition to its direct oxidation capacity, persulfates can be induced to form sulfate radicals, thereby providing free radical reaction mechanisms similar to the hydroxyl radical pathways generated by Fenton's chemistry.

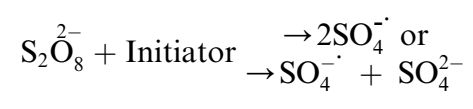

The sulfate radical is one of the strong aqueous oxidizing species with a redox potential of $2.6 \mathrm{~V}$ similar to that of the 
hydroxyl radical $2.8 \mathrm{~V}$. The sulfate radicals are then involved in a series of reactions leading to the degradation of organic compounds. The sulfate radicals produced engages in at least three reaction modes with organic compounds: (i) by abstracting a hydrogen atom from saturated carbon, (ii) by adding to unsaturated or aromatic carbon, (iii) by removing one electron from carboxylate anions and from certain neutral molecules. ${ }^{21}$ These attributes make persulfate a viable option for the treatment of a broad range of organic contaminants in the aqueous medium.

When the concentration of $\mathrm{H}_{2} \mathrm{O}_{2}$ was increased from 2 to 10 ppm, the rate constant increased for both APFP and HPFP. The observed increase in the rate constant was greater for APFP compared to HPFP (Fig. 1). Beyond this concentration, the rate constant decreased for both the process and the role of oxidants $\left(\mathrm{H}_{2} \mathrm{O}_{2} /\right.$ APS $)$ in the rate-controlling steps of the process is negligible especially at higher concentrations. At higher $\mathrm{H}_{2} \mathrm{O}_{2}$ concentrations, the excess hydroxyl radicals generated may undergo recombination reactions or it may take part in unwanted reaction pathways. Similar variations were observed for APS as an oxidant and APS was optimized at $20 \mathrm{ppm}$ for APFP and $30 \mathrm{ppm}$ for HPFP (Fig. 2). The reaction proceeds at a faster rate for $\mathrm{H}_{2} \mathrm{O}_{2}$ as an oxidant compared to APS for both HPFP and APFP. But in the case of APFP the extent of increase in the rate constant is almost 2.5 times higher for $\mathrm{H}_{2} \mathrm{O}_{2}$ compared to APS. The reactivity of APS on the surface of iron powder is slow compared to $\mathrm{H}_{2} \mathrm{O}_{2}$ which accounts for the observed low rate constant for APS. Hydroxyl radicals generated from $\mathrm{H}_{2} \mathrm{O}_{2}$ are either due to direct photolysis or from the reaction of $\mathrm{H}_{2} \mathrm{O}_{2}$ on the iron surface which is a single-step process. But in the case of APS, persulfate radicals on reaction with iron surface initially leads to the formation of sulfate radicals. These sulfate radicals on subsequent reaction with water molecules generate hydroxyl radicals which is two step processes. The kinetics of the later reaction is slow and due to sulfate radicals being more acidic in nature lowers the $\mathrm{pH}$ of the reaction medium. The final $\mathrm{pH}$ of the reaction medium for $\mathrm{H}_{2} \mathrm{O}_{2}$ as an oxidant was found to be 3.2-3.3 for both HPFP and APFP. The final $\mathrm{pH}$ of the reaction medium for HPFP using APS varied from 2.7-2.9 for all the concentrations of APS (10 to $50 \mathrm{ppm}$ ) while for APFP the $\mathrm{pH}$ of the reaction medium drastically reduced from $2.2-2.3$ for higher

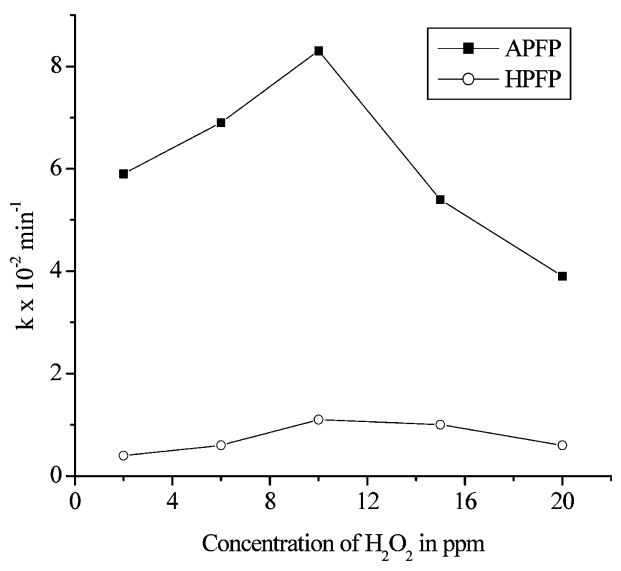

Fig. 1 Effect of $\mathrm{H}_{2} \mathrm{O}_{2}$ on APFP and HPFP.

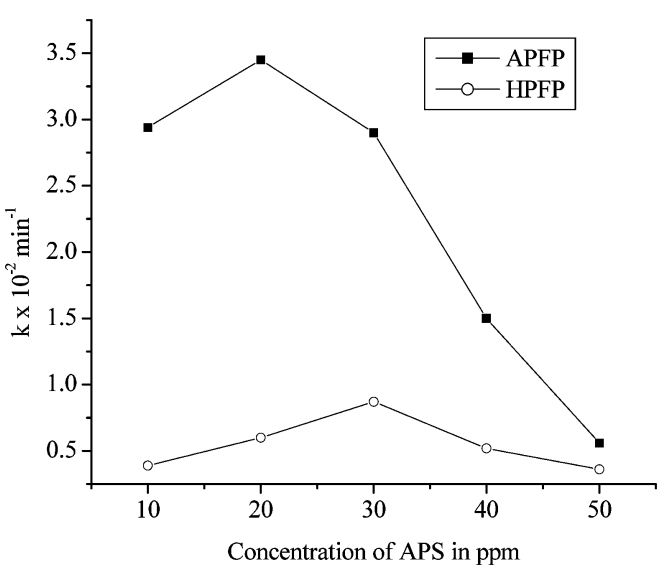

Fig. 2 Effect of APS on APFP and HPFP.

concentration of APS (50 ppm). This decrease in the $\mathrm{pH}$ increases the concentration of protons in the solution acting as hydroxyl radical scavengers. Hence the rate constant drastically decreased to lower values for APFP compared to HPFP. This clearly suggests that the excess protons generated by APS exert negative effects on the degradation rate. Hence it can be concluded that APS effectively lowers the $\mathrm{pH}$ of the reaction medium for APFP compared to HPFP.

\subsection{Effect of iron concentration}

Experiments were performed to study the variation in the degradation efficiency at different catalyst concentrations for both HPFP and APFP. Iron ion concentration is a very important parameter in the Fenton's process as it influences the final $\mathrm{pH}$ of the solution and it also influences the extent of generation of hydroxyl radicals. In the case of APFP, when the concentration of iron powder was increased from 10 to $30 \mathrm{mg}$, the dye was completely decolorised within 15 and 30 min of UV illumination for $\mathrm{H}_{2} \mathrm{O}_{2}$ and APS as oxidants respectively. Beyond this iron concentration, the rate of degradation decreased due to the nonavailability of a sufficient number of dye molecules and the role of oxidants $\left(\mathrm{H}_{2} \mathrm{O}_{2}\right.$ /APS $)$ in the rate-controlling steps of the process is negligible. At high doses of iron, the excess iron might precipitate as iron oxy hydroxide or it can compete for hydroxyl radicals along with the dye molecules and act as an hydroxyl radical scavenger. ${ }^{22}$

$$
\mathrm{Fe}^{2+}+\cdot \mathrm{OH} \rightarrow \mathrm{Fe}^{3+}+\mathrm{OH}^{-}
$$

Hence the catalyst concentration was optimized at $10 \mathrm{mg} / 200$ $\mathrm{ml}\left(50 \mathrm{mg} \mathrm{L}^{-1}\right)$ in APFP. Similar experiments were performed for HPFP and the catalyst concentration was optimized at $15 \mathrm{mg} /$ $200 \mathrm{ml}\left(75 \mathrm{mg} \mathrm{L}^{-1}\right)$ for both the oxidants. The effect of iron concentration on the degradation rate was significantly influenced by the nature of the oxidants used which can be explained as follows: when iron dosage was increased form 10 to $30 \mathrm{mg}$ using $\mathrm{H}_{2} \mathrm{O}_{2}$, the final $\mathrm{pH}$ of the solution was 3.92 and the solution was turbid for APFP. With an increase in the iron dosage from 50 to $150 \mathrm{mg}$, the final $\mathrm{pH}$ of the solution varied from 5.34-5.42 and the precipitate of iron oxy hydroxides coagulates. Further, the precipitates deposit on the iron surface thus blocking the 
process of electron transfer from catalyst surface to the dye molecules and also to the oxidizing agent. This reduces the concentration of hydroxyl radicals in the solution thereby decreasing the degradation efficiency. In the case of APS, the final $\mathrm{pH}$ of the solution was found to be $4.42-4.48$ for $150 \mathrm{mg}$ of iron powder. At these conditions precipitation of iron was not observed. Hence it can be concluded that APS effectively inhibits the precipitation of excess iron by providing excess acidity. However in the case of HPFP, iron precipitation was not observed at higher concentrations probably due to the homogeneous condition of the reaction medium.

\subsection{Effect of substrate concentration}

The degradation efficiency decreases when the concentration of dye is increased. This is due to the insufficient availability of hydroxyl radicals as the other reaction parameters like catalyst/ oxidant concentration, intensity of the light and irradiation time are held constant. Further, with increase in dye concentration, most of the UV photons are absorbed by the dye molecules rather than the catalyst and oxidizing agent which further reduces the generation of hydroxyl radicals in the solution ${ }^{23,24}$ and leads to a photo sensitization process. APFP retains its efficiency to degrade MR even at higher concentrations (20 ppm), while HPFP shows its efficiency only at lower concentrations $(10 \mathrm{ppm})$ beyond which its efficiency decreases drastically. This is attributed to the faster regeneration of $\mathrm{Fe}^{2+}$ ions on the iron surface in APFP which can generate excess hydroxyl radicals. In the case of HPFP the rate of regeneration of $\mathrm{Fe}^{2+}$ ions is slow and hence its efficiency decreases at higher dye concentration. $\mathrm{H}_{2} \mathrm{O}_{2}$ serves as the better oxidizing agent in both the process over the entire range of dye concentration used. Hence APFP can be used as an efficient process for the degradation of the dye at higher concentrations compared to HPFP.

\subsection{Role of scavenger on oxidizing agents}

Hydroxyl radicals play a significant role in the oxidation of pollutants in the photo-Fenton process. To confirm the role of hydroxyl radicals in photo-Fenton's mechanism, the degradation process was carried out in the presence of hydroxyl radical scavengers like methyl alcohol. Methyl alcohol is able to deactivate hydroxyl radicals and their derivatives. ${ }^{25}$ Methanol reacts with hydroxyl radicals with a second order rate constant of $9.7 \times$ $10^{8} \mathrm{~mol}^{-1} \mathrm{~s}^{-1}$ as shown in eqn (20).

$$
\mathrm{CH}_{3} \mathrm{OH}+{ }^{\cdot} \mathrm{OH} \rightarrow \mathrm{CH}_{3} \mathrm{O}^{\cdot}+\mathrm{H}_{2} \mathrm{O}
$$

Though methanol is able to quench hydroxyl radicals, the extent of quenching differs for different oxidants and also for different processes. The decolorisation efficiency decreases from 100 to $32 \%$ for the process $\mathrm{Fe}^{0} / \mathrm{APS} / \mathrm{UV}$ and to $15 \%$ for the process $\mathrm{Fe}^{0} / \mathrm{H}_{2} \mathrm{O}_{2} / \mathrm{UV}$. Similar drastic decreases in the rate constant is from $8.56 \times 10^{-2}$ to $0.46 \times 10^{-2} \mathrm{~min}^{-1}$ for $\mathrm{H}_{2} \mathrm{O}_{2}$ as an oxidant, while marginal decreases in the rate constant from 1.59 $\times 10^{-2}$ to $0.55 \times 10^{-2} \mathrm{~min}^{-1}$ was observed for APS as oxidant for $15 \mathrm{~min}$ of UV illumination. This is because though hydroxyl radicals are quenched by the methanol, sulfate radicals still mediate the degradation process in the absence of hydroxyl radicals. ${ }^{25}$ However for HPFP, decolorisation efficiency decreased to $84 \%$ and $68 \%$ for the process $\mathrm{Fe}^{2+} / \mathrm{APS} / \mathrm{UV}$ and $\mathrm{Fe}^{2+} / \mathrm{H}_{2} \mathrm{O}_{2} / \mathrm{UV}$, respectively. The corresponding rate constants decreased from $0.87 \times 10^{-2}$ to $0.56 \times 10^{-2} \mathrm{~min}^{-1}$ for APS as oxidant and $1.21 \times 10^{-2}$ to $0.51 \times 10^{-2} \mathrm{~min}^{-1}$ for $\mathrm{H}_{2} \mathrm{O}_{2}$ as oxidant. By considering these changes in the magnitude of rate constant, it can be concluded that APFP generates excess hydroxyl radicals in the presence of $\mathrm{H}_{2} \mathrm{O}_{2}$ as an oxidant.

\subsection{Kinetic studies}

The calculation of apparent first order rate constant for APFP and HPFP at the time period of 16 and 90 min are shown in the Fig. 3 and 4 . The dye solution was decolorised to an extent of $25 \%, 35 \%$ and $57 \%$ for the processes $\mathrm{Fe}^{\circ} /$ dark (A), $\mathrm{Fe}^{\%} / \mathrm{APS} /$ dark (B) and $\mathrm{Fe}^{0} / \mathrm{H}_{2} \mathrm{O}_{2} /$ dark (C) processes, respectively, in $16 \mathrm{~min}$. The dye decolorisation in the presence of $\mathrm{Fe}^{\%}$ dark is due to the formation of iron complexes due to the reaction of iron ions with the dye molecules preferably with the chromophore of MR. ${ }^{26}$ The lower efficiency of the dark process can be accounted due to the formation of stable iron complexes. The presence of oxidants like $\mathrm{H}_{2} \mathrm{O}_{2}$ /APS, increases the decolorisation efficiency compared to the $\mathrm{Fe}^{\mathrm{o}}$ /dark process. Iron powder under acidic conditions gets oxidized to $\mathrm{Fe}^{2+}$ ions, which further reacts with $\mathrm{H}_{2} \mathrm{O}_{2} /$ APS to generate hydroxyl radicals as shown in the eqn (8), (9) and (15). In the presence of oxidants alone (in the dark condition), dye decolorisation was almost negligible. For the process $\mathrm{Fe}^{2+} /$ dark no significant dye decolorisation took place due to the formation of stable iron complexes in comparison with process (A). The azo chromophore can be reduced to amines on the iron surface even in dark conditions, which accounts for higher efficiency of $\mathrm{Fe}^{0}$ / dark compared to $\mathrm{Fe}^{2+} /$ dark process. ${ }^{27}$ Nearly $15-23 \%$ of the dye was decolorised for the process $\mathrm{Fe}^{2+} / \mathrm{APS} /$ dark and $\mathrm{Fe}^{2+} / \mathrm{H}_{2} \mathrm{O}_{2} /$ dark which suggests that both the oxidants showed comparable oxidation efficiency in the dark.

On UV irradiation for $15 \mathrm{~min}$, the decolorsiation efficiency for the processes A, B and C increased up to $32 \%, 48 \%$ and $100 \%$ respectively. The enhancement in the efficiency of $\mathrm{Fe}^{0} / \mathrm{UV}$ process is due to the fact that iron complexes formed in the dark can be destroyed under UV irradiation and the iron ions can

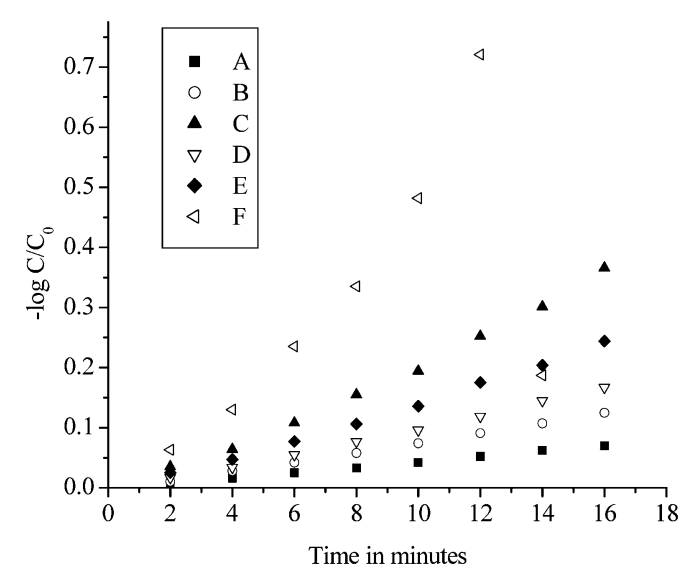

Fig. 3 Plot of $-\log C / \mathrm{C}_{0}$ versus time for various oxidation processes using $\mathrm{Fe}^{0}$ as the catalyst. A. $\mathrm{Fe}^{0} /$ dark, B. $\mathrm{Fe}^{0} / \mathrm{APS}, \mathrm{C} . \mathrm{Fe}^{0} / \mathrm{H}_{2} \mathrm{O}_{2}$, D. $\mathrm{Fe}^{0} /$ UV, E. $\mathrm{Fe}^{0} / \mathrm{APS} / \mathrm{UV}, \mathrm{F}$. $\mathrm{Fe}^{0} / \mathrm{H}_{2} \mathrm{O}_{2} / \mathrm{UV}$. 


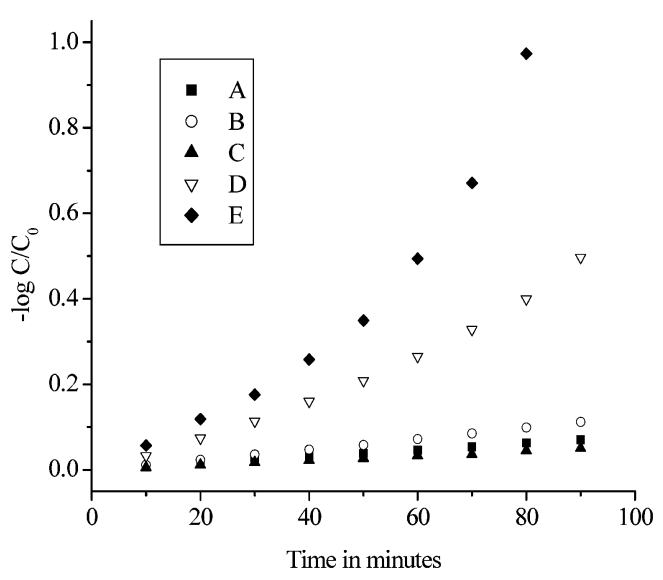

Fig. 4 Plot of $-\log C / \mathrm{C}_{0}$ versus time for various oxidation processes using $\mathrm{Fe}^{2+}$ as the catalyst. A. $\mathrm{Fe}^{2+} / \mathrm{APS}, \mathrm{B} . \mathrm{Fe}^{2+} / \mathrm{H}_{2} \mathrm{O}_{2}, \mathrm{C}$. $\mathrm{Fe}^{2+} / \mathrm{UV}, \mathrm{D}$. $\mathrm{Fe}^{2+} / \mathrm{APS} / \mathrm{UV}, \mathrm{E} . \mathrm{Fe}^{2+} / \mathrm{H}_{2} \mathrm{O}_{2} / \mathrm{UV}$.

return to iron regeneration cycle for active participation in the cyclic photo-Fenton process. $^{28}$ The generation of hydroxyl radicals by the oxidants alone and the photolysis of dye molecules additionally contribute to the overall enhancement in the decolorisation process. In addition, photo reduction of $\mathrm{Fe}^{3+}$ to $\mathrm{Fe}^{2+}$ ions takes place at a faster rate on the iron surface in $\mathrm{APFP}^{29}$ as shown in eqn (21).

$$
2 \mathrm{Fe}^{3+}+\mathrm{Fe}^{0} \rightarrow 3 \mathrm{Fe}^{2+}
$$

The $\%$ decolorisation of the above mentioned dark homogeneous Fenton process increases up to 11, 68 and $100 \%$ for 90 minutes of UV illumination respectively. The low decolorisation efficiency in the HPFP process can be accounted to the slow photo reduction process of ferric ions to ferrous ions.

The rate constant calculated for $\mathrm{H}_{2} \mathrm{O}_{2} / \mathrm{UV}$ process is two times higher than APS/UV process. This difference can be attributed to the fact that the direct photolysis of $\mathrm{H}_{2} \mathrm{O}_{2}$ yields two hydroxyl radicals, while one hydroxyl radical is generated along with a proton by the APS as shown in eqn (15). Since the reaction was carried out in acidic conditions ( $\mathrm{pH} 3)$, the additional protons generated lower the $\mathrm{pH}$ of the reaction medium and act as hydroxyl radical scavengers.

The rate constant calculated for the process $\mathrm{Fe}^{0} / \mathrm{H}_{2} \mathrm{O}_{2} / \mathrm{UV}$ is 3.75 times higher than that of $\mathrm{Fe}^{0} / \mathrm{H}_{2} \mathrm{O}_{2} /$ dark, while the rate constant for $\mathrm{Fe}^{2+} / \mathrm{H}_{2} \mathrm{O}_{2} / \mathrm{UV}$ is ten times higher than that of $\mathrm{Fe}^{2+} /$ $\mathrm{H}_{2} \mathrm{O}_{2} /$ dark. The higher efficiency observed for both HPFP and APFP under illumination is mainly due to faster back photo reduction of $\mathrm{Fe}^{3+}$ ions to $\mathrm{Fe}^{2+}$ ions. The reduced $\mathrm{Fe}^{2+}$ ions can react with oxidants generating hydroxyl radicals thereby increasing the efficiency of the process. The rate constant calculated for the process $\mathrm{Fe}^{0} / \mathrm{H}_{2} \mathrm{O}_{2} / \mathrm{UV}$ is 7 times greater than $\mathrm{Fe}^{2+} / \mathrm{H}_{2} \mathrm{O}_{2} / \mathrm{UV}$ due to the fact that $\mathrm{Fe}^{3+}$ ions so formed reduces to $\mathrm{Fe}^{2+}$ on the iron surface at a faster rate compared to homogeneous conditions.

The percentage of dye decolorisation can be compared for $\mathrm{Fe}^{0}$. $\mathrm{H}_{2} \mathrm{O}_{2}$ /dark and $\mathrm{Fe}^{0} / \mathrm{APS} / \mathrm{UV}$ process, both showing almost similar decolorisation efficiency. This is due to the fact that $\mathrm{Fe}^{0}$ oxidizes to $\mathrm{Fe}^{2+}$ under acidic conditions $(\mathrm{pH} 3)$ and reacts with $\mathrm{H}_{2} \mathrm{O}_{2}$ generating hydroxyl radicals as shown in eqn (8). Further reducing properties of the metallic iron surface enhances the process even in the dark.

The similarity in the rate of decolorisation for the process $\mathrm{H}_{2} \mathrm{O}_{2} / \mathrm{UV}$ and $\mathrm{Fe}^{\%} /$ dark can be accounted in the following way: the hydroxyl radicals generated from the direct photolysis of $\mathrm{H}_{2} \mathrm{O}_{2}$ attacks at the active site of azo chromophore yielding hydroyxlated products resulting in decolorisation as shown in the Scheme 2. This kinetics of decolorisation are almost equal to the reducing nature of the iron surface which decolorises the dye yielding amine substituted products. These results suggest that iron powder is an efficient catalyst and can be used in heterogeneous photocatalysis. In all the above mentioned oxidation processes APFP process showed higher efficiency than their homogeneous counterparts.

The rate constant for the kinetics of decolorisation by various oxidation processes is of the order: $\mathrm{Fe}^{0} / \mathrm{H}_{2} \mathrm{O}_{2} / \mathrm{UV}>\mathrm{Fe}^{0} / \mathrm{H}_{2} \mathrm{O}_{2}>$ $\mathrm{Fe}^{0} / \mathrm{APS} / \mathrm{UV}>\mathrm{Fe}^{2+} / \mathrm{H}_{2} \mathrm{O}_{2} / \mathrm{UV}>\mathrm{Fe}^{0} / \mathrm{UV}>\mathrm{Fe}^{0} / \mathrm{APS} /$ dark $>\mathrm{Fe}^{0} /$ dark $\approx \mathrm{H}_{2} \mathrm{O}_{2} / \mathrm{UV}>\mathrm{Fe}^{2+} / \mathrm{APS} / \mathrm{UV}>\mathrm{APS} / \mathrm{UV}>\mathrm{Fe}^{2+} / \mathrm{H}_{2} \mathrm{O}_{2} /$ dark $>\mathrm{Fe}^{2+} / \mathrm{APS} /$ dark $\approx \mathrm{Fe}^{2+} / \mathrm{UV}$. The process efficiency $(\Phi)$ implies the effectiveness of the present method. The process efficiency can be defined as the concentration of the pollutant degraded divided by the amount of energy in terms of intensity and exposure surface area time ${ }^{-1}$.

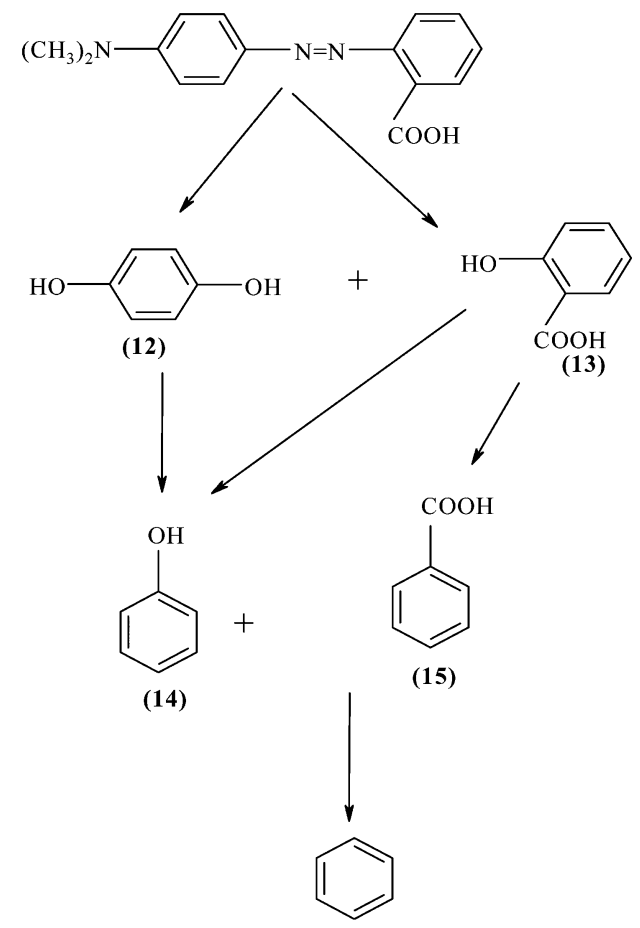

(16)

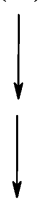

$$
\mathrm{CO}_{2}+\mathrm{H}_{2} \mathrm{O}
$$

Scheme 2 Probable degradation pathway for MR by HPFP. 
Table $1 \%$ decolorisation, rate constant and process efficiency for various oxidation processes ${ }^{a}$

\begin{tabular}{|c|c|c|c|}
\hline Oxidation processes & $\%$ decolorisation & $\begin{array}{l}\text { Rate constant from }-\log C / C_{0} \\
\text { versus time plot } \times 10^{-2} / \mathrm{min}^{-1}\end{array}$ & $\begin{array}{l}\text { Process efficiency }(\Phi) \times 10^{-12} / \mathrm{ppm} \\
\text { Einstein }^{-1}\end{array}$ \\
\hline UV/APS & 12 & 0.35 & 10.92 \\
\hline $\mathrm{Fe}^{0} /$ dark & 25 & 0.74 & 22.75 \\
\hline $\mathrm{Fe}^{2+} /$ dark & 0 & 0.00 & 0 \\
\hline $\mathrm{Fe}^{0} / \mathrm{APS} /$ dark & 35 & 0.96 & 31.85 \\
\hline $\mathrm{Fe}^{0} / \mathrm{H}_{2} \mathrm{O}_{2} /$ dark & 57 & 2.28 & 51.87 \\
\hline $\mathrm{Fe}^{0} / \mathrm{UV}$ & 32 & 1.06 & 29.12 \\
\hline $\mathrm{Fe}^{2+} / \mathrm{UV}$ & 11 & 0.05 & 1.782 \\
\hline $\mathrm{Fe}^{0} / \mathrm{APS} / \mathrm{UV}$ & 48 & 1.59 & 43.68 \\
\hline $\mathrm{Fe}^{0} / \mathrm{H}_{2} \mathrm{O}_{2} / \mathrm{UV}$ & 100 & 8.56 & 91.00 \\
\hline $\mathrm{Fe}^{2+} / \mathrm{APS} / \mathrm{UV}$ & 68 & 0.56 & 11.01 \\
\hline $\mathrm{Fe}^{2+} / \mathrm{H}_{2} \mathrm{O}_{2} / \mathrm{UV}$ & 100 & 1.21 & 16.20 \\
\hline
\end{tabular}

$$
\Phi=\frac{C_{0}-C}{\text { t.I.S }}
$$

$C_{0}$ is the initial concentration of the dye substrate and $C$ is the concentration at time, $t$ and $\left(C_{0}-C\right)$ denotes the reduced concentration of the dye in ppm. $I$ is the irradiation intensity $[I=$ Einstein $/ \mathrm{m}^{2} \mathrm{~s}=8.36 \times \lambda(\mathrm{nm}) \times$ power $($ Watt $\left.)\right]($ where $\lambda$ is 370 $\mathrm{nm}$ and power is $125 \mathrm{~W}$ ). ' $S$ ' denotes the solution irradiated plane surface area is $176 \mathrm{~cm}^{2}$ and $t$ represents the irradiation time in minutes. The performance and quantum efficiency of the process is characterized by the process efficiency. APFP shows higher process efficiency than their homogeneous counterparts (Table 1).

\subsection{GC-MS analysis}

\subsection{Degradation by APFP}

The mass spectrum recorded at the time of decolorisation of the dye for the process $\mathrm{Fe}^{0} / \mathrm{H}_{2} \mathrm{O}_{2} / \mathrm{UV}$ (16 min) shows $\mathrm{m} / z$ peaks at 136, 93 and 122 attributed to the formation of 4,4-N,N-dimethyl aniline (1), aniline (2) and benzoic acid (3). The intermediate (1) is formed due to the complete reduction of azo bonds to amines on the iron surface. The intermediate (2) is formed by the decarboxylation of adduct $\mathrm{C}_{6} \mathrm{H}_{4} \mathrm{NH}_{2} \mathrm{COOH}$, while the intermediate (3) is formed by the loss of $-\mathrm{NH}_{2}$ as $\mathrm{NH}_{2} \mathrm{OH}$. The solution after $40 \mathrm{~min}$ of UV irradiation showed $\mathrm{m} / \mathrm{z}$ peaks at 94,110 corresponding to the formation of hydroxylated aromatic derivatives like phenol (4) and 1,4 dihydroxy benzene (5). The $\mathrm{m} / \mathrm{z}$ peaks at 123 and 78 correspond to the formation of nitrobenzene (6) and benzene (7), respectively. The dealkylation of $\mathrm{N}, \mathrm{N}$-dimethyl group followed by the loss of amine group and subsequent hydroxylation leads to the formation of 1,4 dihydroxy benzene and phenol, respectively. The intermediate aniline (2) further undergoes oxidation to give nitrobenzene (6). The decarboxylation of intermediate (3) results in the formation of benzene (7). The solution after $45 \mathrm{~min}$ of irradiation shows only one $\mathrm{m} / \mathrm{z}$ peak at 108 corresponding to the formation of hydroquinone (8). After one hour of irradiation mass spectrum shows $\mathrm{m} / \mathrm{z}$ peaks at 46,90 and 76 is due to the formation of simple aliphatic carboxylic acids like formic acid (9), oxalic acid (10) and glyoxalic acid (11), respectively. Ring opening reaction of intermediate (8) results in the formation of the above intermediates. After $120 \mathrm{~min}$ of UV irradiation, the mass spectrum showed no characteristic peaks belonging to any functional group confirming the complete mineralization of the dye. Based on the intermediates, a probable degradation pathway has been proposed in Scheme 1.

\subsection{Degradation by HPFP}

The solution at the time of decolorisation shows two $\mathrm{m} / \mathrm{z}$ peaks at 138 and 110 corresponding to the formation of 2,hydroxy benzoic acid (12) and 1,4 dihydroxy benzene (13). The attack of hydroxyl radicals at the site of the azo bond and terminal $N, N$ dimethyl chain results in the formation of above intermediates. The solution irradiated after $3.5 \mathrm{~h}$ shows two $\mathrm{m} / \mathrm{z}$ peaks at 94 and 122 corresponding to the formation of phenol (14) and benzoic acid (15). Phenol might result from the decarboxylation of intermediate (13) and also due to the dehydroxylation of intermediate (12). The mass spectrum recorded at $4 \mathrm{~h}$ of irradiation shows an intense $\mathrm{m} / \mathrm{z}$ peak at 78 corresponding to the formation of benzene (16). The dehydroxylation and decarboxylation of the intermediates (14) and (15) might lead to the formation of benzene. After $4.5 \mathrm{~h}$ of irradiation no characteristic peaks were found in mass spectrum. Based on the intermediates, a probable degradation pathway is proposed in Scheme 2.

\section{Conclusion}

The degradation of MR was investigated by APFP and HPFP using $\mathrm{H}_{2} \mathrm{O}_{2}$ and APS as oxidants. APFP showed higher process efficiency and rate constant than their homogeneous counterparts. $\mathrm{H}_{2} \mathrm{O}_{2}$ served as a better oxidant for both the oxidation processes. The reactivity of the APS is lower probably due to the excess generation of protons which showed negative effect on the degradation rate by scavenging hydroxyl radicals. However, APS effectively inhibited the precipitation of iron by providing excess acidity to the reaction medium which is an essential condition for Fenton's process. The higher efficiency of APFP is attributed to the faster reduction of $\mathrm{Fe}^{3+}$ to $\mathrm{Fe}^{2+}$ ions on the iron surface. The 
degradation pathway concluded that the initial mechanism in the APFP is the reduction of azo bonds to amines while in the case of HPFP it is the oxidation of azo bonds to hydroxylated intermediates. With optimization, the degradation using APFP can be a novel technology for the degradation of azo dye.

\section{Acknowledgements}

Financial assistance from UGC Major Research Project (20072010), Government of India is greatly acknowledged.

\section{References}

1 U. Pagga and D. Brown, Chemosphere, 1986, 15, 479.

2 D. Brown and B. Hamburger, Chemosphere, 1987, 16, 1539.

3 S. Chinwetkitvanich, M. Tuntoolvest and T. Panswad, Water Research, 2000, 34, 2223.

4 G. L. Vaughman and E. J. Weber, Environmental Science and Technology, 1994, 28, 267.

5 Gui-Peng Yang, Yu-Jue Wang, Xian-Chi Gao and Xue Kun Zhao, Journal of Photochemistry and Photobiology A: Chemistry, 2004, 161, 215.

6 Luis M. Madeira, Carlos A. Costa and J. Herney Ramirez, Catalysis Today, 2005, 107-108, 68.

7 Montserrat Perez-Moya, M. Graells, L. J. del Valle, E. Centelles and H. D. Mansilla, Catalysis Today, 2007, 124, 163.

8 Mariana Neamtu, Ayfer Yedaller, Ilie Siminiceanu and Antonius Kettrup, Journal of Photochemistrty and Photobiology A: Chemistry, 2003, 161, 87.

9 G. Papapolymerou, K. Ntampegliotis, A. Riga, V. Bontozoglou and V. Karayannis, Journal of Hazardous Materials, 2006, 136, 75.

10 Hideyuki Katsumata, Shinsuke Kawabe, Satoshi Kaneco, Tohru Suzuki and Kiyohisa Ohta, Journal of Photochemistry and Photobiology A: Chemistry, 2004, 162, 297.
11 C. Pulgarin, P. Peringer, P. Albers and J. Kiwi, Journal of Molecular Catalysis A: Chemical, 1995, 95, 61 .

12 Khalil Hanna, Roger Matta and Serge Chiron, Science of the Total Environment, 2007, 385, 242.

13 F. Lucking, H. Koser, M. Jank and A. Ritter, Water Research, 1998, 32, 2607-2614.

14 Natalija Koprivanac, Hrvoje Kusic, Ana Loncaric Bozic and Iva Selanec, Journal of Hazardous Materials, 2006, 136, 632.

15 M. Perez, F. Torrades, X. Domenech and J. Peral, Water Reserach, 2002, 36, 2703.

16 S. F. Kang, C. H. Liao and M. C. Chen, Chemosphere, 2002, 46, 923.

17 E. Balanosky, F. Herrera, A. Lopez and J. Kiwi, Water Research, 2000, 34, 582.

18 H. J. Benkelberg and P. Warneck, Journal of Physical Chemistry, $1995,99,5214$.

19 C. F. Baes and R. E. Mesmer, The hydrolysis of cations, Wiley Interscience, New York, 1976.

20 D. W. Barnum, Journal of Inorganic Chemistry, 1983, 22, 2297.

21 P. Neta, V. Madhavan, H. Zemel and R. W. Fessemdem, Journal of American Chemical Society, 1977, 99, 163.

$22 \mathrm{~K}$. Barbusinski and J. Majewski, Polish Journal of Environmental Studies, 2003, 12, 151.

23 F. Banat, S. Al-Asheh, M. Al-Rawashdeh and M. Nusair, Desalination, 2005, 181, 225.

24 K. Dutta, S. Mukhopadhyay, S. Bhattacharjee and B. Chaudhuri, Journal of Hazardous Materials, 2001, 84, 57.

25 L. Gomathi Devi, S. Girish Kumar, K. Mohan Reddy and C. Munikrishnappa, Journal of Hazardous Materials, 2008, DOI: 10.1016/j.jhazmat.2008.08.017, In press.

26 W. Choi and H. Park, Journal of Photochemistry and PhotobiologyA: Chemistry, 2003, 151, 241.

27 Jiang Guibin, Zhao Zongshan, Liu Jingfu, Tai Chao, Zhou Qun Fang and Hu Jing Tian, Science in China Series B: Chemistry, 2008, 51, 186.

28 V. Kavitha and K. Palanivelu, Chemosphere, 2004, 55, 1235.

29 David H. Bremner, Arthur E. Burgess, Didier Houllemare and Kyu-Cheol Namkung, Applied Catalysis B: Environmental, 2006, 63, 15 . 